\title{
Prevalence of strongylids of pigs in Ogun State, southwest Nigeria
}

${ }^{1 *}$ Akinkuotu, O. A. ${ }^{2}$ Jacobs, E. B. and ${ }^{2}$ Egbetade, A. O.

${ }^{1}$ Department of Veterinary Microbiology and Parasitology, Federal University of

Agriculture, Abeokuta, Ogun State, Nigeria. ${ }^{2}$ Department of Veterinary Medicine, Federal

University of Agriculture, Abeokuta, Ogun State, Nigeria

*Corresponding author: divinelivn@yahoo.com; akinkuotuoa@,funaab.edu.ng;

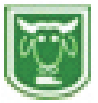

\begin{abstract}
This study was carried out to determine the prevalence of strongyles infecting pigs in Ogun State, Southwestern Nigeria. Faecal samples were collected from 209 pigs which were initially screened by centrifugal sedimentation technique. Faeces positive nematode eggs were then cultured using a modified Baermann's technique. Out of the 36.8\% (77/209) infected pigs, $84.4 \%, 58.4 \%, 57.1 \%, 19.5 \%$ and $6.5 \%$ were for Hyostrongylus rubidus, Trichostrongylus colubriformis, Oesophagostomum spp., Strongyloides ransomi and Dictyocaulus viviparus respectively. Mixed infection with various nematode species accounted for $94.8 \%$ of the prevalence. The infection rate in piglets $(43.7 \%)$ was higher than in weaners and adults without any significant differences. Similarly no significant differences were observed between diarrhoeic and non-diarrhoeic pigs. The results of this study thus showed the economic importance of strongylid nematode infections in intensively reared pigs in Ogun state. Regular screening to ascertain worm load and species involved will facilitate appropriate control and prevention strategies.
\end{abstract}

Keywords: Coproculture, Nigeria, Pigs, Strongyles

\section{Introduction}

Infections with endoparasites, especially helminths, are commonly encountered in pigs of all ages (Roepstorff et al., 2011). Helminth infections, especially by Ascaris, Oesophagostomum, Hyostrongylus and Trichostrongylus, can cause considerable economic losses mainly due to reduction in daily weight gain and poor food conversion (Hale et al., 1985; Romaniuk et al., 1992). Nevertheless, helminth parasites of pigs have generally received much less attention from veterinary parasitologists compared to ruminant helminths research investigations (Roepstorff et al., 2011). This ascertion may not be unconnected with the fact that porcine helminths seldom cause clinical disease and therefore remain largely unrecognized by farmers and most veterinarians, unlike the ruminant helminths which if not controlled, will eventually lead to overt poor performance, severe economic losses or even fatal clinical disease (Roepstorff et al., 2011).

In most helminths infection of pigs, it has been discovered that there is a common trend from high helminth prevalence and infection intensities in traditionally managed swine herd compared to low prevalence and intensities in industrialized production system (Roepstorff et al., 2011). This implies that it is common to find 5-10 helminth species and high infection levels in semi-intensively reared pigs (Ajayi et al., 1988; Nissen et al., 2011). However, Nansen and Roepstorff (1999) reported that traditionally managed indoor herds especially those confined usually habour high infections with few species isolated, namely Ascaris suum and 
Oesophagostomum spp.. Also, in this management system, Trichuris suis and Strongyloides ransomi (threadworm) usually have a low but sporadic occurrence while Hyostrongylus rubidus (red stomach worm) as well as species with indirect life cycles (such as Metastrongylus spp.) are absent indoor (Roepstorff et al., 2011).

In Nigeria, very few investigations on porcine helminths have been carried out (Ajayi et al., 1988; Aernan et al., 2011; Sowemimo et al., 2012). In most published studies on ruminants and pigs in Nigeria, identification of helminth parasites to species level were seldomly carried out but rather faecal egg load are the most assessed. This study was therefore designed to identify various species and to determine the prevalence of stronglyles infecting pigs in Ogun State, South Western Nigeria.

\section{Materials and Methods}

\section{Study period and area}

This study was carried out in Ogun state, Southwest Nigeria. The collection of faecal samples was between September, 2012 and April, 2013.

Sample collection

A total of 209 faecal samples were collected from different pigs reared on five intensively managed piggeries in the state. The pigs were classified on the basis of their age into piglets (1day-3months), weaners (>3months-1year) and adults (>1year) based on records from pig farmers and age classification.

Faecal samples were collected per rectum from individual pigs. For pigs in which rectal sampling was not possible, such as neonates, freshly voided faeces were collected by the use of wooden tongue depressors which were used to scoop up the uppermost layer of freshly voided faeces without contacting the floor. The faeces were then dropped into individual universal sample bottles and labelled appropriately. Samples were transported in an ice pack to the Veterinary Parasitology laboratory, College of Veterinary Medicine, Federal University of Agriculture, Abeokuta, Ogun State, Nigeria and analysed immediately.

Faecal examination

Faecal screening for helminth ova

The faecal samples were initially examined for the presence of nematode eggs by centrifugal sedimentation technique as previously described by Omudu and Amuta (2007)

Coproculture was then carried out on the samples positive for strongyle nematode eggs using a modified Baermann's technique as described by MAFF (1986) and FAO (1998).

Faecal egg culture and identification of infective larvae

After 8-14 days of culturing, two drops of the suspension at the base of the tube were placed on a microscopic slide and viewed at x100 magnification. This step was repeated three times. The infective larvae were identified using morphometric and morphological characteristics according to MAFF (1986) and Jeyathilakan and Sathianesan (2012).

\section{Statistical analysis}

Data were collated and analysed on Statistical Package for Social Sciences (SPSS) Version 16 for Windows. The Chisquared test was used to compare the prevalence rates in different stool consistencies and age groups at 5\% level of significance.

\section{Results}

The results obtained from the centrifugal sedimentation technique revealed that $36.8 \%(77 / 209)$ of the samples were positive for strongylosis.

The result of infective larvae identification 
revealed prevalence rates of $84.4 \%(65 / 77)$, $58.4 \% \quad(45 / 77), \quad 57.1 \% \quad(44 / 77), \quad 19.5 \%$ (15/77) and 6.5\% (5/77) for Hyostrongylus rubidus, Trichostrongylus colubriformis, Oesophagostomum columbianum, Strongyloides ransomi and Dictyocaulus viviparus respectively. Pigs infected with mixed nematode species accounted for $94.8 \%(73 / 77)$ of the total prevalence.

The infection rate was highest in piglets (43.7\%) and lowest in weaners (29.7\%) with no significant difference $(\mathrm{p}>0.05)$ in the prevalence rates between the age categories considered (Table I).

The infection rate in diarrhoeic pigs $(37.8 \%)$ was higher than that observed in non-diarrhoeic ones $(36.0 \%)$. There was however no significant difference $(p=0.798)$ in the infection rates between the two stool consistencies (Table I).

\section{Discussion}

The results of this study revealed that strongyle infections are highly prevalent in pigs in the study area. As at the time of this report, there was no available published data on the prevalence of strongyles in pigs following coproculture using the modified Baermann's technique in Nigeria. The prevalence rate $(36.8 \%)$ recorded in this study was lower than $83.6 \%$ that was recorded in Benue State (Aernan et al., 2011 ) and $91.0 \%$ in Burkina Faso (Tambourna et al., 2006) but slightly higher than $35.8 \%$ recorded in Ibadan, Oyo State (Sowemimo et al., 2012). This may be attributed to the high endemic levels of these nematodes resulting from the high relative humidity and moisture characteristic of the study area which supports the long period of survival of the nematode eggs and larvae in the environment (Emmy-Egbe et al., 2010). The high prevalence rate may also result from the highly unhygienic management practices employed by farmers in the study area in which pens are not regularly cleaned and pigs of different litters are housed together in a pen.

The higher rates of infection, $43.7 \%$, observed in piglets contrasts the reports of Sowemimo et al. (2012), Aernan et al. (2011) and Tambourna et al. (2006). This may be associated with non-attainment of full immunocompetence of this age group of pigs and also the high risk of in-utero transmission of the infective larvae

Table I: Prevalence of strongyles of pigs in relation to age and stool consistencies

\begin{tabular}{ccccc}
\hline Parameters & & $\begin{array}{c}\text { Number } \\
\text { (positive/sampled) }\end{array}$ & $\begin{array}{c}\text { Prevalence } \\
(\mathbf{\%})\end{array}$ & p-value \\
\hline Stool consistency & $\begin{array}{c}\text { Diarrhoeic } \\
\text { Non-diarrhoeic }\end{array}$ & $\begin{array}{c}37 / 98 \\
40 / 111\end{array}$ & 37.8 & 0.798 \\
& & & 36.0 & \\
& Piglets & $31 / 71$ & 43.7 & 0.083 \\
& Weaners & $22 / 74$ & 29.7 & \\
Age categories & Piglets & $31 / 71$ & 43.7 & 0.471 \\
& Adults & $24 / 64$ & 37.5 & \\
& & & & \\
& Weaners & $22 / 74$ & 29.7 & 0.338 \\
\hline
\end{tabular}

*Significant difference exists when $\mathrm{p}<0.05$ 
especially before parturition (Burden and Kendall, 1973; Ng'an'ga et al., 2004).

The high prevalence recorded in nondiarrhoeic and diarrhoeic pigs is similar to the observations of Roepstorff et al. (2011) indicating that there are most infections with these helminths may be subclinical.

From this study, we infer that strongyle infections are of importance in intensively reared pigs in Ogun State, Southwestern Nigeria. We therefore recommend that regular screening and deworming of symptomatic and asymptomatic pigs should be practiced in intensively managed pig farm. This will enhance better productivity and good economic returns.

\section{References}

Aernan, P.T., Agbulu, C.O., Adi, I.A. and Deke, O.S. 2011: Helminth parasites of pork slaughtered in Markurdi, Benue state, Nigeria. Journal of Agriculture and Veterinary Sciences, 3: 35-38.

Ajayi, J.A., Arabs, W.L. and Adeleye, G.A. 1988: Helminths and protozoa of pigs on the Jos Plateau, Nigeria: occurrence, age incidence and seasonal distribution. Bulletin of Animal Health and Production in Africa, 36: 47-54.

Burden, D.J. and Kendall, S.B. 1973: The biology of Hyostrongylus rubidus. VI. The peri-parturient faecal egg output in pigs. Journal of Comparative Pathology, 83(1): 71-78.

Emmy-Egbe, I.O., Jibulu, O.C. and Umeaku, C.U. 2010: Effect of temperature and moisture on the hatchability of human intestinal helminthes eggs. Natural and Applied Sciences Journal, 11(1): 1-6.

Food and Agriculture Organization (FAO) Animal Health Manual 1998: Epidemiology, Diagnosis and Control of helminth parasites of swine, $3^{\text {rd }}$ Edition.

Hale, O.M., Stewart, T.B. and Marti, O.G. 1985: Influence of an experimental infection of Ascaris suum on performance of pigs. Journal of Animal Science, 60: 220-225.

Jeyathilakan, N. and Sathianesan, V. 2012: Comparative morphometry of infective larvae of common nematode parasites of cattle in Kerala. Tamilnadu Journal of Veterinary and Animal Sciences, 8(1): 50-53.

MAFF 1986: Ministry of Agriculture, Fisheries and Food. Manual of Veterinary Parasitological Laboratory Techniques, 3rd Ed., HMSO, London.

Nansen, P. and Roepstorff, A. 1999 Parasitic helminths of the pig: factors influencing transmission and infection levels. International Journal of Parasitology, 29:877-891.

Ng'an'ga, C.J., Munyua, W.K., Maingi, N. and Kanyari, P.W.N. 2004: Occurrence of peri-parturient rise in Trichostrongylid nematode egg output in Dorper ewes in a semi-arid area of Kajiado district of Kenya. Acta Tropica, 92(3): 213-218.

Nissen, S., Poulsen, I.H., Nejsum, P., Olsen, A., Roepstorff, A., RubaireAkiiki, C. and Thamsborg, S.M. (2011): Prevalence of gastrointestinal nematodes in growing pigs in Kabale District in Uganda. Tropical Animal Health and Production, 43: 567-572.

Omudu, E.A. and Amuta, E.U. 2007: Parasitology and Urban livestock farming in Nigeria: prevalence of ova in faecal and soil samples and animal ectoparasites in Makurdi. Journal of South African Veterinary Association, 78(1): 40-45.

Roepstorff, A., Mejer, H., Nejsum, P. and Thamsborg, S.M. 2011: Helminth 
parasites in pigs: New challenges in pig production and current research highlights. Veterinary Parasitology, 180: 72-81.

Romaniuk, K., Wajda, S. and Szelagiewicz, M. 1992: The influence of anthelmintics used at a late stage of fattening on carcass yield and meat quality in pigs. Med. Weter. 48: 324-326.

Sowemimo, O.A., Asaolu, S.O., Adegoke, F.O. and Ayanniyi, O.O.(2012: Epidemiological survey of gastrointestinal parasites of pigs in
Ibadan, Southwest Nigeria. Journal of Public Health and Epidemiology, 4(10): 294-298.

Tamboura, H.H., Banga-Mboko, H., Maes, D., Youssao, I., Traore, A., Bayala, B. and Dembele, M.A. 2006: Prevalence of common gastrointestinal nematode parasites in scavenging pigs of different ages and sexes in Eastern Centre Province, Burkina Faso. Onderskpoort. Journal of Veterinary Research, 73:53-60.

Received: $10^{\text {th }}$ December, 2013

Accepted: $30^{\text {th }}$ September, 2014 